\title{
Rede de tecnologia do Amazonas: fonte informacional para tomada de decisão
}

\author{
Thiago Giordano de Souza Siqueira, Célia Regina Simonetti Barbalho
}

\begin{abstract}
Resumo
Introdução: Debate os resultados de um projeto de Iniciação Científica sobre o fluxo da informação para a gestão empresarial a partir do serviço "Rede de Tecnologia" oferecido pelo Núcleo de Inovação e Empreendedorismo do Instituto Euvaldo Lodi. Método: A pesquisa caracterizou-se como exploratório-descritiva fazendo-se uso do método quali-quantitativo e empregandose pesquisa bibliográfica e de campo. Resultados: Analisa a forma como os empreendedores da cidade de Manaus utilizam as informações fornecidas pelo serviço de informação em seu ambiente organizacional. Identifica as necessidades da demanda e de que forma as informações são aplicadas na gestão ou nos processos de inovação. Revela que a maior parte dos sujeitos da pesquisa é composta de microempresas com menos de um ano de atuação no mercado voltadas ao setor comercial. Conclusões: Evidencia-se a procura por informação mercadológica, seguido da procura por informação sobre criação/registro de empresa, bem como informação sobre fornecedores, em sua maioria com enfoque técnico ou mercadológico. Para parte dos sujeitos, a informação fornecida foi aplicada no estabelecimento do foco no negócio em que atua, existindo uma parcela de empreendedores para a qual o serviço não possibilitou aplicabilidade alguma devido às informações não apresentarem o resultado esperado.
\end{abstract}

\section{Palavras-chave}

Gestão organizacional. Informação para negócios. Serviços de informação. Rede de Tecnologia do Amazonas (RETEC). Instituto Euvaldo Lodi (IEL).

\section{Introdução}

O ambiente dinâmico do século XXI impõe às organizações investimentos em inovação $\mathrm{e}$ busca por melhorias contínuas, devendo dispor de informações precisas no momento certo de modo a subsidiar suas decisões.

Com a propagação e evolução das tecnologias de informação e comunicação (TICs) oportunizouse a disponibilização de informações em larga escala que, em muitos casos, no lugar de facilitar o acesso e uso criou barreiras para o usuário, tendo em vista que o processo de seleção e recuperação é lento e a disponibilização para tomada de decisão não possui a celeridade e precisão desejada.
Nesse contexto surgiu o Núcleo de Inovação e Empreendedorismo do Instituto Euvaldo Lodi (IEL), que atua por meio da Rede de Tecnologia do Amazonas (RETEC/AM) e instituições parceiras, tais como: FIEAM $^{1}$, SESI $^{2}$, SENAI ${ }^{3}$, SEBRAE/AM ${ }^{4}$ e outras, com o objetivo de fornecer informações para a gestão empresarial, sendo capaz de oferecer suporte e intermediar serviços e produtos para o desenvolvimento do negócio.

Cotejando necessidade e oferta, este estudo tem como ponto central examinar os tipos de demandas dos usuários da RETEC/ $A M$, identificando quais são as informações solicitadas e como elas auxiliam nos processos decisórios das empresas na cidade de Manaus, de modo a traçar o perfil dos usuários do serviço, tipificar a demanda dos usuários, identificar

\footnotetext{
${ }^{1}$ Federação das Indústrias do Estado do Amazonas.

${ }^{2}$ Serviço Social da Indústria.

${ }^{3}$ Serviço Nacional de Aprendizagem Industrial.

${ }^{4}$ Serviço Brasileiro de Apoio às Micro e Pequenas Empresas do Amazonas.
} 
quais informações os usuários costumam buscar para auxiliar no processo decisório e, ao final, diferenciar como são aplicadas as informações fornecidas.

O objeto de investigação está situado na RETEC/ AM localizada no Estado de Manaus, a qual se encontra subordinada ao Instituto Euvaldo Lodi (IEL), entidade criada em 1969 pela Confederação Nacional da Indústria (CNI) com a finalidade de promover a interação entre a indústria $\mathrm{e}$ a universidade. Atualmente o IEL é o órgão responsável também em oferecer serviços voltados para o aprimoramento da gestão e capacitação empresarial, com o objetivo de contribuir com o desenvolvimento e fortalecimento da indústria brasileira no mercado nacional e internacional.

Tal serviço de informação proporciona, principalmente para os micros, pequenos e empreendedores individuais, acesso gratuito ao conhecimento necessário para que alcancem melhores índices de crescimento, de competitividade, de qualidade de produtos e serviços e de desempenho de mercado. A base de dados do serviço se constrói a partir das demandas dos usuários. As informações para negócios são distribuídas em formato eletrônico, adequandose, na medida do possível, àquelas existentes no perfil previamente cadastrado pelos usuários, podendo ser baseadas conforme as necessidades, facilidade de uso, qualidade, confiabilidade das informações, adaptabilidade à realidade local, e propósitos de economia de tempo ou custo.

Visando a melhor compreensão, seguem alguns aspectos conceituais e de definição de "informação para negócios" permitindo um maior conhecimento, identificando características de modo a possibilitar o debate a respeito da temática.

\section{Informação para negócios}

A informação é o insumo que movimenta a economia mundial, e organizações capazes de dominar as habilidades informacionais se sobressairão no mercado. Segundo Peter Drucker apud McGee e Prusak (1994, p. 211), informação: "[...] são dados dotados de importância e propósito". De fato, dados em si mesmos não têm finalidade útil, mas quando agregado de valores, contextos, aplicações na organização, tornam-se úteis e logo se transformam em informação.

Um dos muitos recursos que compõem uma organização éa informação. Apesar de, na maioria das vezes fluir implicitamente no processo gerencial, se faz necessário utilizá-la de maneira inteligente para assegurar a competitividade e melhorias na gestão organizacional.

De acordo com Cavalcanti (1995, p. 5) “[...] quando a organização conseguir disponibilizar a informação certa no momento certo, esta ação permitirá à empresa uma vantagem competitiva”. Em ambientes de constante mutação, tais informações quando de rápido acesso, de proveniência confiável e de forma precisa, contribuem para a sobrevivência e o crescimento do negócio. Entretanto, o emprego da informação no contexto de negócios se configura como um meio, o que implica na necessidade de um gestor capaz de compreendê-la, bem como adequála a cada procedimento conforme o nível de importância, assegurando seu valor estratégico.

Ao referir-se a informação para negócios, Vernon (1984) apud Borges e Campello (1997, p. 150) destaca:

Informações para negócios são dados, fatos e estatísticas publicados, necessários à tomada de decisão nas organizações de negócios, públicas ou privadas, bem como no governo. Inclui informações mercadológicas, financeiras, sobre bancos e empresas, leis e regulamentos de impostos, informações econômicas e comerciais, bem como informação factual sobre o ambiente no qual os negócios se realizam.

Percebe-se a informação para negócios como todo e qualquer dado que visa subsidiar as decisões de uma organização.

Durante muito tempo foi comum encontrar na literatura o conceito de informação para negócios de forma implícita ou, ainda, como sinônimo 
do termo informação tecnológica. Porém, é oportuno destacar que apesar da proximidade trata-se de terminologias distintas, sendo necessário conhecer as diferenças entre elas para ter clareza do que se pretende estudar ou mesmo para efetuar a busca de informação para solucionar algum problema.

Informação tecnológica é um conceito voltado às práticas operacionais (modo de fazer) e ao processo produtivo, a qual possibilita a inclusão no termo "informações para negócios", esta por sua vez, está voltada aos processos gerenciais, auxiliando na tomada de decisão. Logo, há focos distintos, ainda que inter-relacionados.

A prestação de serviços de informação para negócios visa fomentar estratégias que prospectem inovação e processos de gestão eficaz. A respeito disso Abell apud Borges e Carvalho (1998, p. 77) destaca a importância de

[...] identificar necessidades, promover meios confiáveis de captação e manipulação dessas informações, bem como promover o acesso à informação.

O termo informação para negócios, originado na Grã-Bretanha e conhecido mundialmente, e principalmente nos países desenvolvidos, por business information passou a ser cada vez mais presente na literatura e no meio empresarial brasileiro. Isso ocorre pelo fato de que as tendências globais, na medida em que cresce o número de empresas instaladas, demandam gestores de informações eficazes, os quais, por sua vez, necessitam de conhecimentos específicos para obter e tratar a informação para subsidiar o processo decisório. Tais informações devem estar suficientemente agregadas de valor para que possam de alguma forma, gerar mudança no campo de atuação da organização.

Gerir a informação de forma estratégica não é uma tarefa simples quanto parece. Trata-se dealgo muito complexo se for considerada a quantidade de informação disponível, motivo pelo qual é importante um planejamento, tornando-se este um instrumento para monitorar se as vantagens estão sendo alcançadas de fato. Por meio dessa prática será possível definir o que fazer e o que não fazer, garantindo melhores resultados.

\section{Materiais e métodos}

A pesquisa classifica-se quanto aos objetivos em exploratório-descritiva, pois buscou compreender a demanda e o uso da informação disponibilizada pela RETEC/AM com intuito de arrolar elementos que possam qualificar a oferta, e, por conseguinte, o desempenho das empresas e empreendedores que utilizam o serviço.

Quanto aos procedimentos a pesquisa configurase como estudo de caso, considerando que a RETEC/AM é o locus da investigação, sendo examinada sua ação, permitindo assim, uma melhor análise dos procedimentos quando da oferta de um serviço de informação.

Quanto à natureza dos dados a pesquisa configurase como qualitativo-quantitativa, preocupandose não apenas com a compreensão e interpretação do ato informacional, mas também com um olhar para o entendimento dos efeitos causados com o uso da informação prestada.

A coleta de dados ocorreu em dois momentos: primeiro com a identificação, junto a RETEC/AM das demandas e respostas efetuadas no período em estudo; depois por meio de questionários disponibilizados eletronicamente, ou aplicado por ligação telefônica utilizando o critério de acessibilidade.

Visando obter dados resultados mais focados, optou-se por estabelecer uma amostra de 20\% da quantidade de demanda dos anos 2009 e 2010. O outro critério utilizado para seleção foi a quantidade de demandas encaminhadas, optando-se por entrevistar os usuários que solicitaram mais de duas nesse período.

O procedimento inicial de coleta de dados se deu pela análise dos cadastros existentes no banco de dados, seguida pela extração dos dados para contato. Em um primeiro momento, 
encaminhou-se um e-mail com o formulário disponibilizado como pesquisa de satisfação dos usuários da RETEC/AM que os gestores do programa consideraram ser a forma adequada, por se configurar em um meio de disponibilizar e motivar ao mesmo tempo os usuários a oferecerem suas respostas.

Surgiram algumas dificuldades operacionais ao desenvolvimento da pesquisa, devido à obsolescência das informações registradas no banco de dados, havendo números telefônicos e $e$-mails incorretos, o que causou uma defasagem entre o número de usuários reais e os cadastrados.

Levando em conta os critérios preestabelecidos e tendo sido concedido um prazo para a devolução dos formulários respondidos, a amostra foi composta de 55 usuários, que representam um recorte de $10 \%$ do universo total de 550 potenciais respondentes. No entanto, dessa amostra 8 usuários ( $15 \%$ da amostra) responderam o formulário até a data de tabulação dos dados da pesquisa, considerando estes como sujeitos da pesquisa.

\section{Resultados}

Segundo o perfil, os usuários caracterizamse em sua maioria por microempresas (57\%), havendo a presença de uma empresa de pequeno porte (14\%), uma empresa de consultoria (14\%) e duas que se enquadram como pessoa física (15\%). A presença de microempresas como as participantes, que estão mais envolvidas com o serviço, possivelmente se dá pela necessidade de aumentar sua capacidade competitiva, além da compreensão de seu papel no desenvolvimento econômico regional.

Considerando a taxa de mortalidade para microempresas no Brasil, verificou-se o tempo de atuação destas no mercado, constatando-se que $52 \%$ dos usuários possuem um empreendimento com menos de um ano. Possivelmente, a demanda ao serviço ocorreu pelo fato de não terem conhecimento do ramo em que atuam e busquem informações para construir uma base nova para desenvolver o negócio.

Percebe-se que a busca por informações está relacionada à dificuldade para se estabilizar no mercado e, por conseguinte, há uma alta demanda por informações que possam subsidiar melhorias nas decisões e, dessa forma, contribuir para a sobrevivência.

A respeito da mortalidade e sobrevivência das Micro e Pequenas Empresas (MPEs), Chiavenato (2008, p. 15), cita que "[...] nos novos negócios, a mortalidade prematura é elevadíssima, pois os riscos são inúmeros e os perigos não faltam". $\mathrm{O}$ autor afirma que os empreendedores devem buscar neutralizar as ameaças micro e macro ambientais além de identificar oportunidades, principalmente nos momentos turbulentos.

Pesquisa do SEBRAE Nacional (SEBRAE/NA, 2007) avaliou as taxas de mortalidade das MPEs brasileiras e seus fatores condicionantes. Nesta, o Amazonas, no ano de 2005 apresentou uma taxa de $24,2 \%$, enquanto a média brasileira foi de $22 \%$. O estudo elencou uma série de fatores que corroboram para a dificuldade no gerenciamento do empreendimento e o seu posterior fechamento, destacando-se as falhas gerenciais tais como ponto/local inadequado, falta de conhecimentos gerenciais, desconhecimento do mercado, e causas econômicas.

Nota-se que, nestas, há uma estrutura simplificada e centralizada, onde muitas vezes, a tomada de decisão é pautada na experiência, o que torna o processo gerencial subjetivo e desprovido de métodos e técnicas que corroborem para o processo gerencial, dificultando - devido ao despreparo - o acesso e/ou expansão da micro ou pequena empresa no mercado.

Entretanto, a tomada de decisão de algumas MPEs, quando baseadas apenas na experiência do empreendedor, é pautada uma política de sobrevivência e dificulta a prospecção de melhorias devido o fato dele não ser capaz de realizar um planejamento baseado nos objetivos da empresa. 
Os fatos expostos são preocupantes, uma vez que a pesquisa da Global Entrepreneurship Monitor (GEM, 2010) revelou que Brasil alcançou, em 2010, a maior taxa de empreendedorismo entre países membros do G20 (grupo que integra as maiores economias do mundo) e do BRIC, grupo que reúne os emergentes Brasil, Rússia, Índia e China. No entanto, a característica principal do empreendedorismo em outros países está nas pessoas que buscam empreender por oportunidade, enquanto no Brasil, surge por necessidade, o que corresponde a ingressar em um negócio por falta de melhores alternativas, sem preparo para ingressar no mercado, o que torna a atividade uma aventura pela busca de oportunidades de sobrevivência.

Quanto à atividade desenvolvida pelos sujeitos da pesquisa, constata-se a predominância da procura do serviço pelos empreendedores do setor comercial (75\%), prestação de serviços (25\%), seguidos pela indústria (17\%). Os dados apontam uma tendência da representatividade do setor de comércio, em concordância com a pesquisa do GEM (2010, p.67), que avalia o período de 2002 a 2010, demonstrando que $28 \%$ das atividades brasileiras encontram-se no comércio varejista, permanecendo com maior prioridade os empreendedores, seguido pelo setor de serviços voltados ao consumidor, o qual ganha espaço sobre o setor industrial. O setor industrial talvez represente uma pequena fatia dos usuários da RETEC/AM, quer pela existência de programas específicos, e pelo fato de - em sua maioria - as indústrias possuírem estruturas robustas que agregam à organização um setor de Pesquisa e Desenvolvimento (P\&D) ou de Inteligência Competitiva (IC) para suprir as necessidades informacionais, especialmente para aquelas instaladas no Polo Industrial de Manaus (PIM).

No que tange à natureza dos tipos de serviços mais solicitados, buscou-se conhecer qual a razão principal do envio de demandas à RETEC/AM. Nota-se a predominância motivada pelo início de um negócio (45\%) seguida da ampliação de negócio (45\%). Pressupõe-se que tal fato ocorre devido o empreendedor entender ser esta uma oportunidade de se preparar seja para ingressar ou ampliar o negócio sem tantos riscos, podendo traçar e avaliar suas estratégias antes mesmo de dar início as suas atividades, buscando orientações para tornar seu empreendimento viável e competitivo.

Verificou-se no sistema de gerenciamento da RETEC/AM a natureza das informações mais solicitadas pelos sujeitos da pesquisa. Há maior procura por informação mercadológica (5 respostas), seguida por informação sobre criação/registro de empresa (4 respostas) e sobre fornecedores (4 respostas).

Certamente, os empreendedores preocupam-se em buscar dados e fatos a respeito das variáveis do ambiente onde estão inseridos para subsidiar decisões estratégicas e diminuir os riscos de um gerenciamento deficiente, possibilitando ainda análise do mercado e adequação às mudanças.

A respeito da forma que os usuários obtiveram conhecimento dos serviços oferecidos pela RETEC/AM, constatou-se que a maioria o fez por meio de indicação de amigos (34\%) o que sustenta que os contatos pessoais continuam sendo a principal fonte de informação destes empreendedores; seguido de acesso a home page (22\%) do IEL/AM ou do Sistema FIEAM, que possui um link de divulgação.

Entre as fontes informacionais utilizadas pelos empreendedores para conhecer as novidades do seu ramo de atuação, destaca-se a utilização $\mathrm{da}$ internet (quatro respostas), seguida da participação em cursos e palestras, em sua maioria sobre gestão de micro e pequenos negócios (três respostas), ou ainda através dos programas de apoio e eventos promovidos pelo SEBRAE/ AM (duas respostas). Outros apontam que não dispõem de outras fontes (duas respostas) e apenas um sujeito busca informações em livros ou revistas.

A análise dos resultados acima demonstra que a maioria dos respondentes possui acesso à internet, ficando aparente que possuem competência 
para utilizar as TICs disponíveis para promover melhorias em seus negócios, além da mesma atuar como mecanismo colaborativo de aceleração da divulgação de novos conhecimentos. Indica ainda que, geralmente as informações são obtidas por meio de contato pessoal com grau significativo de informalidade.

A respeito da variável participação em cursos e palestras nota-se, por parte dos próprios respondentes, a vontade de intensificar a capacidade empreendedora. Porém há aqueles que os fazem não pela oportunidade, mas pela necessidade ou dificuldade em montar um plano de negócios e/ou viabilidade financeira, visto que o mesmo é solicitado como pré-requisito por alguns programas que viabilizam o acesso às linhas de concessão de crédito, tais como os Programas de Financiamento às Microempresas e Empresas de Pequeno Porte (FNE-MPE) ofertados pelo Banco do Brasil e Banco da Amazônia.

Muitos empreendedores acreditam que o sucesso do negócio é proveniente do conhecimento do ramo e do capital inicial para abertura. A premissa não é totalmente errônea, no entanto, mais que conhecer o ramo de atuação e ter dinheiro suficiente para iniciar o negócio, é necessário estar preparado para superar as adversidades do mercado e dessa forma eliminar fatores que possam levá-las ao fracasso.

Após identificar o perfil dos usuários avaliou-se o nível de satisfação com os produtos e serviços oferecidos. Quanto às respostas relativas à satisfação informacional, observa-se que 50\% confirmaram a qualidade da informação recebida e a classificaram como excelente, ou seja, ficaram altamente satisfeitos com as respostas. Uma parte $(25 \%)$ considerou as informações recebidas como ótimas e a outra parte (25\%) afirmou que as respostas não atenderam às suas expectativas.

Exploraram-se os fatores que levaram a frustração dos usuários cujas expectativas não foram atendidas. Na fala dos sujeitos duas barreiras corroboram para a não satisfação: o tempo para solução da demanda e consequentemente a demora na chegada da resposta, e a exposição da metodologia em detrimento das ferramentas necessárias para execução efetiva.

Outro fator que possivelmente contribui para a não satisfação está relacionado à construção de resposta não adequada, ocasionada pela interpretação da demanda de forma equivocada por parte do usuário e do facilitador (respondente), uma vez que a contato é realizado via Internet, ocorrendo perdas de informações, que, se detalhadas, poderia fornecer respostas mais precisas.

Souto (2010, p. 70) afirma que "A interação verbal é importante porque pode ajudar o usuário a representar o contexto da informação de que necessita, principalmente quando os perfis dos usuários forem representados por palavras, uma vez que palavras isoladas podem ter diferentes significados". Assim, aumentando o nível de interação entre usuário e o serviço, facilitaria a identificação com detalhes das necessidades informacionais do usuário, pois nem sempre a demanda expressa representa a necessidade informacional.

Sugere-se uma entrevista pontual e direta com o usuário, possibilitando uma realimentação antes mesmo da construção da resposta, buscando-se reduzir a discrepância entre a demanda desejada e a resposta obtida.

Tais elementos podem ser casos isolados, o que demanda pela necessidade de uma pesquisa mais aprofundada nesse aspecto, qual seja a qualidade das informações e satisfação dos usuários. É oportuno atentar para a gestão da qualidade em serviços de informação, que deve buscar os efeitos da qualidade sob a perspectiva do usuário, compreendido como cliente do serviço.

É relevante na literatura a exposição de Valls e Vergueiro (2006, p. 127) sobre a gestão da qualidade em serviços de informação no Brasil cujo foco é no cliente, sendo capaz de captar as suas reais expectativas, "buscando atendê-las e antes de tudo, entendê-las". 
Ainda segundo os autores, os usuários assumem um papel mais ativo e exigente, portanto conforme Vergueiro (2002, p. 84) apud Valls e Vergueiro (2006) os gestores do serviço “[...] parecem entender que seus clientes não têm uma ideia muito clara daquilo que querem e nem condições de avaliar corretamente o que recebem".

Na área de Ciência da Informação é possível qualificar um serviço de informação a partir do uso da informação fornecida, a respeito disso Barreto (2005) apud Souto (2010, p. 59) destaca que "[...] não basta atingir o receptor há que criar conhecimento modificador em pessoas [...]". Destaca-se a importância da aplicabilidade das informações.

Nesse contexto, examinou-se a forma como as informações fornecidas pela RETEC/AM tem aplicabilidade real nos negócios. A análise dos resultados demonstra que para parte dos sujeitos (23\%) houve aplicação da informação fornecida para estabelecer o foco no negócio em que atua ao passo que para outros $22 \%$ não houve aplicabilidade alguma, devido às informações não apresentarem o resultado esperado. Apresentouse também a aplicabilidade para formação de preço (11\%), abertura de empresa (11\%), diferenciar produtos e serviços (11\%) e esclarecer dúvidas (11\%).

É possível que tais informações não atingissem as expectativas dos usuários devido à descrição da demanda não está bem caracterizada, ou ainda a partir da interpretação de Ramos, Carvalho e Cunha (2006) pela existência de: informações incompletas; informações erradas; falta de viabilidade técnica; e falta de recursos financeiros para execução.

Outro ponto investigado foi o entendimento da importância do serviço na tomada de decisão no negócio. A análise dos resultados demonstra que a maior parte dos sujeitos identificou a importância da RETEC/AM como um serviço de orientação (44\%), no sentido de esclarecer dúvidas e direcionar para ações que visaram melhorias nos processos de gestão ou dos produtos e serviços que oferecem. Outro aspecto exposto foi a utilização do serviço como ferramenta de viabilidade para materializar ideias $(22 \%$ das respostas) previamente estabelecidas, mas sem conhecimento para executá-las.

Em um contexto onde a informação serve como tomada de decisão, uma vez que orienta os negócios, é fundamental que além de chegar no momento certo, ela deve ter origem em fontes confiáveis, para que não leve o empreendedor a tomar decisões equivocadas.

Observada a não satisfação com algumas respostas, buscou-se conhecer quais as fontes informacionais utilizadas, visando conhecer sua credibilidade. Essas se encontram exclusivamente em meio eletrônico, possível devido o advento da Internet que atualmente. Torna-se um meio de acesso, troca e compartilhamento de informações mais utilizado pela rápida acessibilidade e por demandar pouco espaço físico para a realização do serviço prestado pela RETEC/AM.

Sobre as fontes identificadas, a maior parte está ligada ao governo, ou seja, são instituições e banco de dados bem estruturados, pressupondose que disponibilizam informações consistentes e confiáveis, uma vez que se responsabilizam pela atualização e qualidade das informações veiculadas.

\section{Considerações finais}

As empresas constantemente precisam anteciparse às variáveis ambientais, no entanto, muitas ainda não possuem a percepção da maneira como gerar negócios e decidem os seus rumos tendo como insumo o empirismo. Dentre os fatores encontrados, que, o que contribui para que os empreendedores busquem à RETEC/AM é a predominância motivada pelo início de um empreendimento, adicionalmente a motivação segue para a ampliação do mesmo. Tal fato corrobora para que mais da metade dos usuários seja microempresas, com menos de um ano de atuação no mercado e situadas no setor comercial.

É fato que alguns empreendedores não possuem competência informacional para gerir seus 
negócios e torná-lo competitivo, daí a importância dos produtos e serviços da RETEC/AM para orientá-los. Entretanto, os produtos e serviços disponibilizados não atingem de modo efetivo os empreendimentos, pois as MPEs e (Empresas de Pequeno Porte) EPPs, por possuírem particularidades que vão além das estruturas físicas e organizacionais, deparam-se ainda com a barreira financeira para execução de possíveis soluções, contudo precisam buscar ferramentas que possibilitem superar tais barreiras.

A principal limitação do estudo é seu caráter exploratório, não conclusivo e contando com um número limitado de respondentes comparado ao universo potencial de pesquisa. Sugere-se que para maior aproveitamento e compreensão da demanda real dos usuários seja construído um formulário, devendo ser preenchido em uma entrevista in loco para ser possível elencar as possíveis demandas de forma coerente, dessa forma, aumentando a eficiência e eficácia das informações fornecidas e contatos futuros para estabelecer uma rede de trabalho. Como pesquisas futuras sugere-se a avaliação das fontes informacionais utilizadas pela RETEC/AM.

\section{Referências}

BORGES, M. E. N.; CARVALHO, N. G. de M. Produtos e serviços de informação para negócios no Brasil: características. Ciência da Informação, Brasília, v. 27, n. 1, p. 76-81, jan. 1998. Disponível em: <http://dx.doi. org/10.1590/S0100-19651998000100010>. Acesso em: 9 out. 2012.

BORGES, M. E. N.; CAMPELLO, B. S. A Organização da informação para negócios no Brasil. Perspectivas em Ciência da Informação, v. 2, n. 2, p. 149-161, jul./dez. 1997. Disponível em: <http://portaldeperiodicos.eci. ufmg.br/index.php/pci/article/view/5/418>. Acesso em: 9 out. 2012.

CAVALCANTI, E. P. Revolução da informação: algumas reflexões. Caderno de Pesquisas em Administração, v. 1, n. 1, p. 1-7, jul./dez. 1995. Disponível em: <http:// www.ead.fea.usp.br/cad-pesq/arquivos/C01-art06. pdf>. Acesso em: 9 out. 2012.

CHIAVENATO, I. Empreendedorismo: dando asas ao espírito empreendedor. São Paulo: Saraiva, 2008.
GLOBAL ENTREPRENEURISHIP MONITOR.

Empreendedorismo no Brasil: 2010. Curitiba: IBQP, 2010. Disponível em: <http://www.agenciasebrae.com. br/anexo_download.kmf? cod=314>. Acesso em: 27 abr. 2011.

MCGEE, J.; PRUSAK, L. Gerenciamento estratégico da informação: aumente a competitividade de sua empresa utilizando a informação como uma ferramenta estratégica. 18. ed. Rio de Janeiro: Campus, 1994.

RAMOS, H. C.; CARVALHO, F., CUNHA, M. B. Avaliação do uso do Serviço Brasileiro de Respostas Técnicas: um serviço de informação destinada à microempresa brasileira. Ciência da Informação, v. 35, n. 3, p. 255269, set./dez. 2006. Disponível em: <http://dx.doi. org/10.1590/S0100-19652006000300025>. Acesso em: 9 out. 2012.

SEBRAE NACIONAL. Fatores condicionantes e taxa de mortalidade de empresas no Brasil de 2003 a 2005. Brasília: SEBRAE/NA, ago. 2007.

SOUTO, L. F. Informação seletiva, mediação e tecnologia: A evolução dos serviços de disseminação seletiva da informação. Rio de Janeiro: Interciência, 2010.

VALLS, V. M.; VERGUEIRO, W. A gestão da qualidade em serviços de informação no Brasil: uma revisão de literatura de 1997 a 2006. Perspectivas em Ciência da Informação, v. 11, n. 1, p. 118-36, jan./abr. 2006. Disponível em: <http://dx.doi.org/10.1590/S141399362006000100010>. Acesso em: 9 out. 2012. 
Amazon network technology: informational source for decision making

\section{Abstract}

Introduction: Debates the flow of strategic information for business management offered by a service from the Center of Innovation and Entrepreneurship Euvaldo Lodi Institute (Network Technology). Method: It is an exploratory and descriptive research, using qualitative and quantitative methods, literature search and field research. Results: Analyzes how the entrepreneurs of the city of Manaus at their organizational environment use the information provided by this information service. Identifies the needs of demand and how the information is applied in the management and innovation processes. Reveals that the majority of research subjects' act in the commercial sector and are composed of micro-enterprises with less than one year of experience. Conclusions: Shows the demand for marketing information as the main interest, followed by requests for information about how to create/register the company, and technical and marketing information about vendors. The enterprises applied the information provided by the information service to establish the business focus, although part of the research subjects' didn't use the responses provided by the service/ program considering that they were not suitable for the results intended.

\section{Keywords}

Organizational management. Business information. Amazonas Technology Network (RETEC). Euvaldo Lodi Institute (IEL).

\section{Agradecimentos:}

Agradeço o apoio e receptividade da equipe do Núcleo de Inovação e Empreendedorismo do IEL/AM. À Prof. ${ }^{a}$ Célia Regina Simonetti Barbalho pela autonomia a mim concedida no desenvolvimento desta pesquisa, pelo incentivo, discussões esclarecedoras e por mostrar que pesquisa se faz acima de tudo com persistência e dedicação.

Recebido em 26 de junho de 2012

Aceito em 27 de agosto de 2012

\section{Sobre os autores:}

\section{Thiago Giordano de Souza Siqueira}

Graduado em Biblioteconomia - Universidade Federal do Amazonas - (UFAM)

thiago.giordano@gmail.com

\section{Célia Regina Simonetti Barbalho}

Graduada em Biblioteconomia - Universidade Federal do Amazonas - (UFAM), Mestre em Ciência da Informação - Pontifícia Universidade Católica de Campinas (PUCl CAMPINAS), Doutora em Comunicação e Semiótica Pontifícia Universidade Católica de São Paulo (PUC/SP) celia.simonetti@gmail.com

Como citar este artigo:

SIQUEIRA, T. G. S.; BARBALHO, C. R. S. Rede de tecnologia do amazonas: fonte informacional para tomada de decisão. AtoZ, Curitiba, v. 1, n. 2, p. 26-34, jan./dez. 2012. Disponivel em: <http://www.atoz.ufpr.br>. Acesso em: 